\title{
Peptide Growth Factors and Inflammation, Tissue Repair, and Cancer
}

\author{
Michael B. Sporn and Anita B. Roberts \\ Laboratory of Chemoprevention, National Cancer Institute, Bethesda, Maryland 20892
}

\section{Introduction}

The concept that cancer is an aberrancy of the physiological processes of inflammation and tissue repair is very old. 200 years ago John Hunter described the neoplastic process as a perverted version of inflammation (1). The relationship between the inflammatory process and the development of malignancy was a central theme of Virchow's studies in the 1800s (2). Many of his classic studies dealt with the histological relationships and similarities of abscesses, tubercles, and true cancers (1). However, with the discovery of specific microorganisms as etiologic agents for infectious disease, the topics of inflammation and cancer were split in two and were increasingly thought of as discrete subjects over the next 100 years.

It is only within the past 10 years, as a result of studies of biochemical mechanisms for the control of proliferation of cells and cellular matrix, that these two separate fields have again begun to merge. Historically, the subject of proliferation has been emphasized in biochemical studies of cancer cells. Only recently, as attention has focused on mechanisms of invasion and metastasis (3), has major effort been given to biochemical studies of the role of cellular matrix in carcinogenesis. Conversely, studies of inflammation and repair, particularly of inflammatory diseases such as rheumatoid arthritis, have historically focused on cell matrix; only more recently have the proliferative events in tissue repair been studied from a biochemical perspective. However, it is now apparent that it is essential to understand the role of cell matrix if one wishes to understand the processes of invasion and metastasis in cancer, and it is equally apparent that the control of cell proliferation is an essential phenomenon in inflammatory and repair processes.

Thus, biochemical mechanisms by which cells and tissues respond to injury and initiate the repair process are now known to be highly relevant to the study of carcinogenesis. Although studies of these mechanisms have often used malignant transformed cells and have dealt with the role of oncogenes and peptide growth factors involved in neoplasia, it is now evident that the data that have been obtained are equally relevant to the study of many proliferative diseases other than cancer (4), including such common entities as atherosclerosis (5) and rheumatoid arthritis (6). Because the process of transformation is exaggerated in the cancer cell, cancer has served to focus attention on the relevant mechanisms of other proliferative diseases. Indeed, we are suggesting that the transformed state is essentially a physiological one, not a pathological one, unless it is expressed out of context, i.e., permanently switched on, expressed at the wrong time, or expressed in excessive amounts.

Received for publication 30 January 1986.

The Journal of Clinical Investigation, Inc.

Volume 78, August 1986, 329-332
The cancer cell may thus be viewed as a permanent clone for investigating mechanisms of inflammation and repair, which are pertinent to the study of nonneoplastic proliferative disease. It is likely we will find the same mediators of cell growth and matrix elaboration to be involved in malignancy, atherogenesis, rheumatoid arthritis, and other diseases of connective tissue. The crux of many of these studies has been the role of peptide growth factors; it is now clear that the same growth factors that play a key role in the malignant process in cancer cells are expressed physiologically by cells that mediate inflammation and repair, namely platelets, macrophages, and lymphocytes. In this review we briefly outline some key advances to date along with prospects for the future. The following topics will be considered: (a) the role of peptide growth factors in carcinogenesis, $(b)$ the similarities between carcinogenesis and the processes of inflammation and repair, $(c)$ the role of peptide growth factors in inflammation and repair, $(d)$ the relevance of the above to proliferative diseases other than cancer, and $(e)$ the possible therapeutic implications of this approach.

\section{Peptide growth factors and carcinogenesis}

It is now well established that the cancer cell is relatively autonomous with respect to growth control by exogenous signaling molecules, and that this state of autonomy contributes to the cancer cell's malignant behavior. The concept of autocrine action of peptide growth factors provides a unifying theme for the mechanisms accounting for such autonomy $(7,8)$. There are three principal mechanisms whereby a cancer cell may become relatively independent of external growth control by peptide growth factors. (a) It may synthesize, secrete, and respond to excessive amounts of peptide growth factors themselves. (b) It may synthesize and express excessive amounts of functional receptors for growth factors. (c) It may have excessive amplification of the signal generated at a receptor for a growth factor. There are now examples of specific oncogenes that contribute to carcinogenesis by each of these three respective mechanisms, such as the sis gene $(9,10)$, which codes for the production of the B chain of platelet-derived growth factor (PDGF); ${ }^{1}$ the $e r b-B$ gene (11), which codes for the production of a truncated epidermal growth factor (EGF) receptor; and the ras gene (12), which is involved in postreceptor signaling. Thus, the action of many oncogenes results in the activation of biochemical pathways involving peptide growth factors. If the expression of an oncogene is transient, there will be a transient increased expression of growth factor action. However, if an oncogene or one of its control elements is mutated, there may be permanent increased

1. Abbreviations used in this paper: EGF, epidermal growth factor; FGF, fibroblast growth factor; PDGF, platelet-derived growth factor; TGFalpha, transforming growth factor-alpha; TGF-beta, transforming growth factor-beta. 
expression of growth factor action, as occurs in many cancer cells.

It should be emphasized, though, that the transient expression of oncogenes is often a physiological process associated with normal cell division and embryogenesis, and as we will describe later, the transient action of peptide growth factors is a part of the normal processes of inflammation and repair. Thus, the mere expression of an oncogene is not sufficient cause for malignancy. Indeed, we should consider that the transformed state of growth in cells may be quite physiological if the process is reversible, as occurs during inflammation and tissue repair, as well as during embryogenesis. The inception of development of the embryo from the moment of fertilization of the ovum is the ultimate transformation, and we should expect to find mechanisms that are common to embryogenesis and carcinogenesis. Only when regulation is lost does pathology result.

Although many peptide growth factors will eventually be found to exert an autocrine action in cancer cells, current research has focused on three principal autocrine peptides, namely, transforming growth factor-alpha (TGF-alpha), transforming growth factor-beta (TGF-beta), and PDGF. TGF-alpha is a structural homolog of EGF (13), binds to the same receptor (whether it should be called the TGF-alpha receptor or the EGF receptor is a question of semantics), and, indeed, is the embryonic analog of EGF (14). The genes for TGF-alpha and EGF are entirely different in terms of their structure and chromosomal locations. Although a 50 amino acid-processed molecule isolated from human melanoma cells was the first TGF-alpha to be purified to homogeneity (13), it is now clear that human TGFalpha is synthesized from a message that encodes 160 amino acids (15), and that this larger molecule may be equally important with respect to the cancer cell. It is well established that many human cancer cells synthesize TGF-alpha, and that the expression of several oncogenes, in turn, leads to increased expression of TGF-alpha, even though the oncogenes themselves do not code for TGF-alpha (16). The possibility that inflammatory cells may produce TGF-alpha is currently under active study.

Although TGF-beta shares a common nomenclature with TGF-alpha, it is a totally distinct molecule, both in terms of its chemical structure and biological activity (16). TGF-beta is a homodimer (molecular weight, 25,000) with each chain consisting of 112 amino acids. TGF-beta, like TGF-alpha, is synthesized by many human cancer cells, and the expression of certain oncogenes can cause elevated expression of TGF-beta. TGF-beta has also been isolated from several nonneoplastic tissues (16), such as platelets, placenta, kidney, and, most recently, bone (17); its potential role in inflammation and repair will be discussed later.

PDGF was the first peptide growth factor to be directly implicated in oncogenesis (18). Peptides resembling PDGF have been found in many different types of cancer cells, including fibrosarcomas $(9,10)$, osteosarcomas $(19,20)$, and common epithelial cancers (21). Like TGF-beta, PDGF is a dimer. However, elucidation of the total structure of human PDGF has been complicated by the presence of two similar chains, $A$ and $B(22)$, and human PDGF may be a mixture of A-A and B-B homodimers, as well as the A-B heterodimer. Unlike TGF-alpha and TGF-beta, which were discovered in transformation assays performed in an attempt to understand the malignant phenotype, PDGF was first isolated as a physiological peptide from human platelets $(23,24)$. Thus, its relevance to the problem of tissue repair has never been in doubt.
Similarities between carcinogenesis and inflammation-repair

It has been known for many years that in order for many tumors to grow in vivo, they must establish a proper stromal and angiogenic reaction to facilitate further development. Such observations were made in the early days of tumor transplantation, and modern studies of the mechanisms of invasiveness and metastasis have continued to focus on the importance of matrix destruction (3), matrix synthesis (25), and angiogenesis (26) as critical determinants of the growth of cancer cells. These are exactly the same processes that are involved in tissue repair and wound healing $(27,28)$. Therefore it is not surprising that a mechanistic analysis of the chemical signals that are involved in tumor cell growth is also germane to the tissue responses that occur during inflammation and tissue repair. As specific peptide growth factors have been identified as participants in the neoplastic transformation of cells, one may therefore expect that the same peptides would have some role in tissue repair and wound healing. Particularly, one might expect such peptides to play a role in the control of collagen breakdown, the recruitment and formation of new fibroblasts, the formation of new collagen and other matrix substances, and the formation of new blood vessels. Indeed, this is exactly what is being found in recent studies of the peptide growth factors that have been identified in platelets, macrophages, and lymphocytes, three of the key cells participating in tissue repair $(27,28)$. As will be described, many of the same peptide growth factors participate in both malignant transformation and tissue repair; the difference between these two phenomena would appear to be whether the expression of the peptides is appropriately controlled or not; rather than their mere presence or absence. As Haddow (29) has elegantly described it, "the wound is a tumor that heals itself."

\section{Peptide growth factors and tissue repair}

The repair of injury begins as soon as tissue damage occurs, and the release of peptide growth factors from injured cells and inflammatory cells is a critical part of this process. PDGF, TGFalpha, and TGF-beta are, again, three peptides that have an important role. Although there may be autocrine action of these peptides in injured cells, it would appear that their paracrine action, driven by their production and release by various inflammatory cells, accounts for the key role of these peptides in the repair process. This is a major difference between tissue repair and cancer; it is the paracrine action of peptide growth factors in repair that allows for a much greater degree of regulation. Although it has recently been shown that injured cells can behave in an autocrine manner (cultured arterial smooth muscle cells from rats suffering trauma to their arterial walls synthesize, release, and respond to peptides that resemble PDGF; 30), it is the inflammatory cells that enter an injured area and provide an orchestrated release of paracrine growth factors, essential for repair of injury. These growth factors then control the recruitment of new cells and the formation of new matrix and new blood vessels necessary for the repair process. Platelets are the first cellular elements in the repair of a wound, followed by neutrophils, and then by macrophages and lymphocytes $(27,28)$.

PDGF, TGF-alpha, and TGF-beta have all recently been shown to participate in the repair process. PDGF is initially released from the alpha-granules of platelets, and is a potent chemoattractant for fibroblasts (31), as well as a mitogen for these cells in the presence of either TGF-alpha or EGF (18). Furthermore, PDGF stimulates the production of collagenase 
by fibroblasts (32) and thus contributes to the remodeling of matrix, an essential feature of tissue repair (33). PDGF, in addition to being released from platelets, has recently been found to be synthesized by and released from activated macrophages $(34,35)$. The role of TGF-alpha in the repair process is just beginning to be investigated; peptides resembling TGF-alpha have been found in platelets (36), activated macrophages (Assoian, R., and H. Stevenson, unpublished observation), and in the ascites fluid of cirrhotic patients (Von Hoff, D., unpublished observation). It is thus clear that it is no longer tenable to believe that TGF-alpha can serve as a specific diagnostic marker of malignancy, as had once been hoped (37). TGF-alpha has a physiological role in the adult animal, a role yet to be completely defined.

TGF-beta appears to have a particularly important role in the repair process. This peptide is found in relatively high concentrations in platelets (36) and has recently been found in activated T lymphocytes (38) as well as in macrophages (Assoian, R., H. Stevenson, and R. Ross, unpublished observation). When injected subcutaneously in newborn mice, it causes a rapid fibrotic and angiogenic response at the site of injection; the new tissue formed is essentially granulation tissue (39). Furthermore, TGF-beta will stimulate the formation of collagen in human or rodent fibroblasts (39). Another recently discovered source of TGF-beta is bone (17). TGF-beta is present in bone in amounts almost 100 -fold greater than those in many other soft tissues. The physiology of TGF-beta in bone is unknown at present, but, again, it may be involved in the control of the formation of collagen or other matrix substances that are relevant to the remodeling and formation of bone matrix. Essentially, all cells have high affinity receptors for TGF-beta, indicating that all cells can potentially respond to this growth factor (Wakefield, L., unpublished observation). In vitro studies indicate that TGFbeta can control the effects of several other peptide growth factors, such as PDGF, TGF-alpha (or EGF), basic fibroblast growth factor (FGF), and interleukin 2, and that it can determine whether a cell responds in a positive or negative manner to such peptides $(16,38,40)$. Thus, TGF-beta can enhance or inhibit the effects of PDGF or EGF in a variety of human and rodent fibroblasts, and is a potent inhibitor of the effects of interleukin 2 on T lymphocytes. We thus propose that TGF-beta should be thought of as a "panregulin" whose function is to control the activities of several other peptide growth factors.

Three other peptides that are highly relevant to the repair process, particularly to its angiogenic component, have recently been identified and characterized. These are acidic and basic FGFs (41) and angiogenin (42). Acidic and basic FGFs bind heparin very strongly and are potent mitogens for vascular endothelial cells $(41,43,44)$. Peptides resembling basic FGF are found in platelets and macrophages. Angiogenin is highly active in inducing capillary formation in the chick chorioallantoic membrane (42), although its cellular mechanism of action is unknown at present. The gene for this peptide has been cloned from a human liver cDNA library (45), while the peptide itself has been isolated from human colon cancer cells (42), again emphasizing the dual role of angiogenesis factors in cancer and tissue repair.

To understand the mechanism of action of all of these peptide growth factors, it must be realized that they act in sets or combinations $(16,36)$, in which each peptide modulates the effects of the next. Peptide growth factors and their receptors are biological signaling mechanisms, and the information conveyed by such signals does not reside in any individual peptide. Rather, they are like the individual symbols of an alphabet or a code, which have little or no meaning by themselves; the meaning of each peptide signal can only be understood within the total context of all of the other signals that are operant in the cell. The participation of many different types of cells in the inflammatory and repair process allows effective integration and control of these signals; it is the loss of this integration and control which is the hallmark of cancer.

\section{Proliferative diseases other than cancer}

The analysis of the role of peptide growth factors that has just been presented obviously relates to many diseases other than cancer in which inflammatory cells drive a proliferative disease process by virtue of their secretion of peptide growth factors. Many common chronic diseases, such as atherosclerosis, rheumatoid arthritis, and hepatic cirrhosis, are characterized by excessive cellular proliferation, as well as by an alteration in collagen formation and destruction. There are many other less common conditions, such as scleroderma and idiopathic pulmonary fibrosis, in which similar mechanisms may also be operant (4). In many of these diseases it would appear that peptide growth factors produced by activated inflammatory cells (macrophages or lymphocytes) are driving the disease process; this analysis should now be extended to granulomatous diseases such as sarcoidosis. To the extent that different types of cancer cells may represent cloned, exaggerated versions of various aspects of the process of tissue repair, the study of carcinogenesis offers an opportunity to understand mechanisms relevant to other proliferative diseases. Although we have focused on three principal peptide growth factors in this review, it is apparent that studies of interleukins, interferons, tumor necrosis factor, lymphotoxin, and other peptide signaling molecules produced by inflammatory cells may also be of major importance in the understanding of proliferative diseases. In the past many of these studies have been hindered by the ill-defined nature of the peptide growth factors; however, with recent advances in peptide chemistry and molecular genetics, these handicaps can now be overcome.

\section{Therapeutic implications}

As common causation mechanisms of cancer and other proliferative diseases are being discovered, there are unique opportunities to intervene in the disease process. The use of antagonists of specific peptide growth factors presents one approach to intervention; the use of monoclonal antibodies to growth factors, growth factor receptors, or other oncogene products, presents another. It is likely that pharmacological agents such as steroids or retinoids may be affecting the expression of peptide growth factors or their receptors. To the extent that disease mechanisms are understood in detail, new rational approaches to disease prevention or treatment may be undertaken. Finally, the study of malignant disease has led to the identification and isolation of new peptide growth factors, which might be useful agents in enhancing the process of tissue repair in the elderly or the debilitated, in enhancing the formation of bone matrix in osteoporosis or after bone injury, or in improving would healing after surgery or trauma.

\section{Acknowledgments}

We are indebted to Edward Harris, Jr., Russell Ross, and Robert Weinberg for many discussions concerning the ideas presented here, and to Richard Assoian and Lalage Wakefield for helpful comments. 


\section{References}

1. Rather, L. J. 1978. The Genesis of Cancer. Johns Hopkins University Press, Baltimore, $262 \mathrm{pp}$.

2. Virchow, R. 1863-1867. Die krankhaften Geschwulste. Berlin.

3. Liotta, L. A. 1986. Cancer Res. 46:1-7.

4. Sporn, M. B., and E. D. Harris, Jr. 1981. Am. J. Med. 70:12311236.

5. Ross, R. 1986. New Engl. J. Med. 314:488-500.

6. Harris, E. D., Jr. 1985. In Textbook of Rheumatology. W. N. Kelley, E. D. Harris, Jr., S. Ruddy, and C. B. Sledge, editors. 2nd ed. W.B. Saunders Co., Philadelphia. 886-915.

7. Sporn, M. B., and A. B. Roberts. 1985. Nature (Lond.). 313:747751.

8. Weinberg, R. A. 1985. Science (Wash. DC). 230:770-776.

9. Doolittle, R. F., M. W. Hunkapiller, L. E. Hood, S. G. Devare,

K. C. Robbins, S. A. Aaronson, and H. N. Antoniades. 1983. Science (Wash. DC). 221:275-277.

10. Waterfield, M. D., G. T. Scrace, N. Whittle, P. Stroobant, A. Johnsson, A. Wasteson, B. Westermark, C.-H. Heldin, J. S. Huang, and T. F. Deuel. 1983. Nature (Lond.). 304:35-39.

11. Downward, J., Y. Yarden, E. Mayes, G. Scrace, N. Totty, P. Stockwell, A. Ullrich, J. Schlessinger, and M. D. Waterfield. 1984. Nature (Lond.). 307:521-527.

12. Gilman, A. G. 1984. Cell. 36:577-579.

13. Marquardt, H., M. W. Hunkapiller, L. E. Hood, D. R. Twardzik, J. E. De Larco, J. R. Stephenson, and G. J. Todaro. 1983. Proc. Natl. Acad. Sci. USA. 80:4684-4688.

14. Lee, D. C., R. Rochford, G. J. Todaro, and L. P. Villarreal. 1985. Mol. Cell Biol. 5:3644-3646.

15. Derynck, R., A. B. Roberts, M. E. Winkler, E. Y. Chen, and D. V. Goeddel. 1984. Cell. 38:287-297.

16. Roberts, A. B., and M. B. Sporn. 1985. Cancer Surv. 4:683-705.

17. Seyedin, S. M., A. Y. Thompson, H. Bentz, D. M. Rosen, J. M. McPherson, A. Conti, N. R. Siegel, G. R. Gallupi, and K. A. Piez. 1986. J. Biol. Chem. 261:5693-5695.

18. Deuel, T. F., A. Kimura, S. Maehama, and B. D. Tong. 1985. Cancer Surv. 4:633-653.

19. Heldin, C., B. Westermark, and A. Wasteson. 1980. J. Cell Physiol. 105:235-246.

20. Graves, D. T., A. J. Owen, and H. N. Antoniades. 1983. Cancer Res. 43:83-87.

21. Bowen-Pope, D. F., A. Vogel, and R. Ross. 1984. Proc. Natl. Acad. Sci. USA. 81:2396-2400.

22. Johnsson, A., C.-H. Heldin, A. Wasteson, B. Westermark, T. F. Deuel, J. S. Huang, P. H. Seeburg, A. Gray, A. Ullrich, G. Scrace, P. Stroobant, and M. D. Waterfield. 1984. EMBO (Eur. Mol. Biol. Organ.) J. 3:921-928.
23. Ross, R., and A. Vogel. 1978. Cell. 14:203-210.

24. Antoniades, H. N., and A. J. Owen. 1984. Hormonal Proteins and Peptides. 12:232-277.

25. Barsky, S. H., C. N. Rao, G. R. Grotendorst, and L. A. Liotta. 1982. Am. J. Pathol. 108:276-283.

26. Folkman, J., and R. S. Cotran. 1976. Int. Rev. Exp. Pathol. 16: 207-248.

27. Wahl, S. M. 1981. In Cellular Functions in Immunity and Inflammation. J. J. Oppenheim, D. L. Rosenstreich, and M. Potter, editors. Elsevier, New York. 453-466.

28. Ross, R. 1968. Biol. Rev. Camb. Philos. Soc. 43:51-96.

29. Haddow, A. 1972. Adv. Cancer Res. 16:181-234.

30. Bowen-Pope, D. F., and R. Seifert. 1985. Cancer Cells (Cold Spring Harbor). 3:183-188.

31. Grotendorst, G. R., H. E. Seppa, H. K. Kleinman, and G. R. Martin. 1981. Proc. Natl. Acad. Sci. USA. 78:3669-3672.

32. Bauer, E. A., T. W. Cooper, J. S. Huang, J. Altman, and T. F. Deuel. 1985. Proc. Natl. Acad. Sci. USA. 82:4132-4136.

33. Harris, E. D., Jr., and S. M. Krane. 1974. New Engl. J. Med. 291:557-563, 605-609, 652-661.

34. Shimokado, K., E. W. Raines, D. K. Madtes, T. B. Barrett, E. P. Benditt, and R. Ross. 1985. Cell. 43:277-286.

35. Martinet, Y., P. B. Bitterman, J. Mornex, G. R. Grotendorst, G. R. Martin, and R. G. Crystal. 1986. Nature (Lond.). 319:158-160.

36. Assoian, R. K., G. R. Grotendorst, D. M. Miller, and M. B. Sporn. 1984. Nature (Lond.). 309:804-806.

37. Twardzik, D. R., S. A. Sherwin, J. Ranchalis, and G. J. Todaro. 1982. J. Natl. Cancer Inst. 69:793-798.

38. Kehrl, J. H., L. M. Wakefield, A. B. Roberts, S. Jakowlew, M. Alvarez-Mon, R. Derynck, M. B. Sporn, and A. S. Fauci. 1986. J. Exp. Med. 163:1037-1050.

39. Roberts, A. B., M. B. Sporn, R. K. Assoian, J. M. Smith, N. S. Roche, L. M. Wakefield, U. I. Heine, L. A. Liotta, V. Falanga, J. H. Kehrl, and A. S. Fauci. Proc. Natl. Acad. Sci. USA. 83:4167-4171.

40. Baird, A. 1986. Endocrinology. 118(Suppl.):289. (Abstr.)

41. Lobb, R. R., J. W. Harper, and J. W. Fett. 1986. Anal. Biochem. 154:1-14.

42. Fett, J. W., D. J. Strydom, R. R. Lobb, E. M. Alderman, J. L. Bethune, J. F. Riordan, and B. L. Vallee. 1985. Biochemistry. 24:54805486.

43. Esch, F., A. Baird, N. Ling, N. Ueno, F. Hill, L. Denoroy, R. Klepper, D. Gospodarowicz, P. Bohlen, and R. Guillemin. 1985. Proc. Natl. Acad. Sci. USA. 82:6507-6511.

44. Burgess, W. H., T. Mehlman, R. Friesel, W. V. Johnson, and T. Maciag. 1985. J. Biol. Chem. 260:11389-11392.

45. Kurachi, K., E. W. Davie, D. J. Strydom, J. F. Riordan, and B. L. Vallee. 1985. Biochemistry. 24:5494-5499. 